\title{
Managing Unwanted Intrusive Thoughts In Obsessive Compulsive Disorder: Relative Effectiveness Of Suppression, Focused-Distraction, and Acceptance
}

\section{Citation}

Najmi, Sadia, Bradley C. Riemann, and Daniel M. Wegner. 2009 Managing unwanted intrusive thoughts in obsessive compulsive disorder: relative effectiveness of suppression, distraction, and acceptance. Behaviour Research and Therapy 47(6): 494-503.

\section{Published Version}

doi:10.1016/j.brat.2009.02.015

\section{Permanent link}

http://nrs.harvard.edu/urn-3:HUL.InstRepos:9275580

\section{Terms of Use}

This article was downloaded from Harvard University's DASH repository, and is made available under the terms and conditions applicable to Open Access Policy Articles, as set forth at http:// nrs.harvard.edu/urn-3:HUL.InstRepos:dash.current.terms-of-use\#OAP

\section{Share Your Story}

The Harvard community has made this article openly available.

Please share how this access benefits you. Submit a story.

\section{Accessibility}


Managing Unwanted Intrusive Thoughts in Obsessive Compulsive Disorder:

Relative Effectiveness of Suppression, Focused-Distraction, and Acceptance

\author{
Sadia Najmi ${ }^{1}$, Bradley C. Riemann ${ }^{2}$, and Daniel M. Wegner ${ }^{3}$ \\ San Diego State University/ University of California, San Diego ${ }^{1}$ \\ Rogers Memorial Hospital ${ }^{2}$ \\ Harvard University ${ }^{3}$
}

Corresponding Author:

Sadia Najmi

San Diego State University

6386 Alvarado Ct., Suite 301

San Diego, CA 92120, USA

E-mail: najmi.sadia@gmail.com

Word Count (includes abstract, text, and references): 10,881 


\begin{abstract}
Suppression is one of various mental control techniques that people may use to manage unwanted thoughts. Evidence suggests that it is at best unsustainable and at worst counterproductive. This leads to the question: If suppression is a futile way to respond to unwanted, intrusive, thoughts, what is a more effective alternative? In the current study, we evaluated the relative effectiveness of suppression and two alternative mental control techniques — focused distraction and acceptance — on the frequency of intrusions and distress associated with them. Results support the claim that suppression is a counterproductive technique for dealing with unwanted, intrusive thoughts in OCD. However, the harmfulness of suppression was reflected primarily in the magnitude of distress and not in intrusion frequency. Focused distraction and acceptance were the more effective techniques for managing clinically significant intrusive thoughts. We discuss implications for the cognitive treatment for OCD.
\end{abstract}

Key Words: Obsessive-Compulsive Disorder, Suppression, Distraction, Acceptance, Intrusive Thoughts 
There exists a large body of evidence to suggest that the management of intrusive thoughts is a tricky enterprise both in normal experience and in disorders of perseverative thinking, such as obsessive compulsive disorder (OCD). For instance, suppression is a commonly used tactic for responding to unwanted thoughts. However, evidence suggests that it is at best an unsustainable and at worst a counterproductive way to deal with nonclinical and clinical obsessions. A question that remains unanswered is: If suppression is a futile way to respond to unwanted thoughts, what then is a more effective alternative? In this research, we assessed the relative effectiveness of suppression and two alternative mental control techniques — focused distraction, and acceptance — on the frequency of intrusions and distress associated with them.

\section{Defining Unwanted Intrusive Thoughts}

Unwanted intrusive thoughts (UITs) surface as symptoms across a surprising range of disorders, from generalized anxiety and OCD to depression and beyond (Clark, 2005). UITs can take many forms. The focus of the present research is on discrete, unwanted thoughts that enter conscious awareness, and that are experienced as nonvolitional, ego-dystonic, distracting, discomforting, and difficult to control.

\section{Suppression of Unwanted Intrusive Thoughts}

Thought suppression is one of a range of strategies that people may use to manage or control thoughts when they trigger unpleasant emotions (Wegner, 1989; Wells \& Davies, 1994). According to the ironic process theory of mental control (Wegner, 1994), any individual engaging in thought suppression is likely to encounter the frequent intrusive return of that thought. This rebound effect - the increased frequency of the thought that was previously the target of suppression- has since been observed with a 
variety of target thoughts (see review by Wenzlaff \& Wegner, 2000). Wegner and Gold's (1995) defensive suppression hypothesis states that thought suppression is more likely to occur for emotional thoughts, both spontaneously in daily life and in the confines of an experiment. Moreover, when thoughts are associated with unpleasant emotions, people are likely to engage in chronic thought suppression (Wegner \& Zanakos, 1994). The counterproductive effects of thought suppression have been observed in experimental studies of UITs (see review by Rassin, 2005), posttraumatic stress disorder (Shipherd \& Beck, 1999), acute stress disorder (Guthrie \& Bryant, 2000; Harvey \& Bryant, 1998) and depression (Dalgleish \& Yiend, 2006; Wenzlaff \& Bates, 1998; Wenzlaff \& Eisenberg, 2001; Wenzlaff, Meir, \& Salas, 2002; Wenzlaff, Wegner, \& Roper, 1988). These studies suggest that although suppression may seem to be an effective solution, it can have profound and unexpected consequences for the psychological influences of the unwanted thoughts.

Suppression of Unwanted Intrusive Thoughts in OCD

A survey conducted by Freeston and Ladoucer (1997) showed that $76 \%$ of individuals with OCD reported attempting to suppress their UITs repeatedly. However, to date, there has not been much investigation of the effects of instructed suppression of UITs in OCD. One problem in conducting the thought suppression experiment with OCD patients is the difficulty of finding an appropriate control condition. Tolin, Abramowitz, Przeworski, and Foa (2002) note that instructing individuals with OCD to suppress a UIT is essentially a "non-intervention" since individuals in the nonsuppression control group are being asked to act against what they would naturally do. In fact, Purdon, Rowa, and Antony (2005) found that individuals with OCD exerted effort to 
suppress their UIT despite explicit instructions not to suppress, and that this suppression effort was correlated with their perceived urgency to control the thought. This may explain the absence of suppression rebound or enhancement effects in the studies of instructed suppression of UITs in clinical samples of OCD patients (Janeck \& Calamari, 1999; Purdon et al., 2005). Tolin et al. (2002) argue that if individuals with OCD have a general deficit in their ability to control thoughts, it will be manifested in their ability to control neutral thoughts. Moreover, this design circumvents the problem of spontaneous suppression of UITs in the OCD control group. Results from the study by Tolin et al. (2002) were consistent with their hypothesis: Individuals with OCD had higher occurrences of a neutral target thought after suppressing than did anxious and nonanxious controls.

However, Purdon (2001) suggests that in order to study the effects of suppression on UITs it may be best to study natural active resistance to the thought (i.e., when participants are instructed to think of anything they like) and then to assess suppression effort afterwards (cf. Wenzlaff \& Wegner, 2000). Moreover, Salkovskis (1996) has argued that obsessional problems are not associated with general deficits but rather with difficulties associated with one or two obsessions in particular. Until this debategeneral inhibitory deficit rather than a bias in OCD—is resolved, our understanding of thought suppression in OCD is likely best advanced by taking into account the suppression of emotionally relevant UITs as well as the no-instruction spontaneous suppression of UITs. The design of the current research reflects this objective.

The initial observations of thought suppression suggested that it is not very successful (Wegner, Schneider, Carter, \& White, 1987). How can we reconcile this with 
findings that neither a rebound nor an enhancement effect occurred in the two studies of instructed suppression of UITs with OCD patients (Janeck \& Calamari, 1999; Purdon et al., 2005)? One possibility is that suppression works temporarily. If so, it serves as a neutralization strategy; that is, it terminates exposure to the obsession thereby curtailing habituation of the anxiety associated with the obsession (Roemer \& Borkovec, 1994) and preventing disconfirmation of the perceived negative consequences of the obsession. Another possibility is that suppression fails. Failed suppression can serve to increase the salience of the UIT and the need to control it in order to avoid the perceived negative consequences. Moreover, failure of suppression is associated with worse mood and faulty appraisals of suppression failure, which may in turn lead to greater effort to suppress (Clark, 2004; Purdon et al., 2005). Conceptualized this way, it may be the case that repeated attempts at suppression serve to exacerbate an already existent obsessional state.

Furthermore, in a comprehensive review of studies of thought suppression, Abramowitz, Tolin, and Street (2001) found evidence for a rebound effect, and concluded that the vast differences in suppression effects found in studies of thought suppression are likely due to methodological differences. Thus, we hypothesize that suppression of UITs in OCD will lead to an increase in the frequency of unwanted thoughts and the distress associated with these thoughts post-suppression (rebound effect).

\section{Alternative Mental Control Techniques}

If suppression of UITs has harmful consequences and hence is an inadvisable response to UITs, what then is a more favorable alternative? The following mental 
control techniques were chosen for investigation on the basis of a theoretical rationale and some prior evidence for their effectiveness in the management of UITs:

Focused-Distraction. Wegner et al. (Experiment 2, 1987) have found that focused distraction can be effective in getting rid of non-clinical UITs. According to the ironic process theory of mental control (Wegner, 1994), successful suppression is achieved by increasing the accessibility of distracter thoughts. Usually when people try to suppress thoughts, they tend to undertake an unfocused distraction strategy-the iterative use of many different distracters rather than just one focus-and experience a rebound of the suppressed thought (Wegner, Schneider, Knutson, \& McMahon, 1991). However, this rebound effect is attenuated when using one focused distracter thought (Wegner et al., 1987). Results of studies of obsessional thoughts have shown that distraction is more effective in reducing distress than is neutralization (Salkovskis, Thorpe, Wahle, Wroe, \& Forrester, 2003), and that distraction is more effective in reducing the frequency of the UITs than is suppression (Salkovskis \& Campbell, 1993).

Focused distraction away from the UIT is identical to focused attention on something that is other than the UIT. The facilitation of strategic attentional control—in particular, learning to change the focus of attention away from the negative, perseverative, thinking that characterizes mood and anxiety disorders- - has been examined recently. For instance, Wells' (2000) Attention Training Technique (ATT) has been successful in reducing symptoms in small studies of panic disorder, social phobia, hypochondriasis, and major depression (Papageorgiou \& Wells, 1998; 2000; Siegle, Ghinassi, \& Thase, 2007; Wells, White, \& Carter, 1997), and Bogels, Mulken, and De Jong's (1997) Task Concentration Training has been effective in reducing symptoms in 
various studies of social phobia (Bogels, 2006; Bogels et al., 1997; Mulkens, Bogels, de Jong, \& Louwers, 2001). Moreover, in a recent study, Watson and Purdon (2008) showed that focused distraction and ATT were equally effective in reducing the frequency of UITs in non-clinical individuals. Thus, to the extent that an increase in attentional control has been linked with a decrease in perseverative thinking, we would expect focused distraction to lead to a reduction in the frequency of intrusive thoughts and distress associated with the thoughts.

Acceptance. A number of studies have shown the effectiveness of acceptancebased approaches to the treatment of psychopathology (Kabat-Zinn et al., 1992; Ma \& Teasdale, 2004; Roemer \& Orsillo, 2007; Teasdale et al., 2000). This approach focuses on increasing the individual's willingness to experience distressing thoughts without attempting to alter their content or frequency (e.g., Hayes, Strosahl, \& Wilson, 1999). Mindful-acceptance-based techniques have been incorporated into cognitive-behavioral treatments for depression (Segal, Williams, \& Teasdale, 2002) and generalized anxiety disorder (Roemer \& Orsillo, 2002). These techniques often consist of metaphors that are aimed at maintaining the individual's observation of the UIT (Acceptance and Commitment Therapy, ACT; Hayes et al., 1999). If, as claimed by its authors, acceptance encourages the simple act of noticing the UIT and discourages struggling with it, we might expect the distress caused by the UIT to lessen without necessarily a reduction in the frequency of the UIT (Bach \& Hayes, 2002). Indeed, recent studies have yielded preliminary evidence for the effectiveness of ACT in the treatment of OCD (Twohig, 2008; Twohig, Hayes, \& Masuda, 2006). 
A recent study with a non-clinical sample has shown the relative effectiveness of an acceptance-based technique as compared to suppression in reducing the distress, but not frequency, associated with UITs (Marcks \& Woods, 2005). There is no research examining distinct mechanisms underlying the effect of acceptance of UITs. However, some clinicians who focus on treatments based on exposure with response prevention (e.g., Foa and Wilson, 2001) recommend responding to UITs using an acceptance-based technique to supplement the exposure exercises. One possibility is that the acceptance technique encourages exposure to the UIT, at the very least by explicitly discouraging suppression of the UIT. Wenzlaff (2005) has suggested that one way of understanding acceptance-based therapies is to see how they work against the individual's tendency to try to suppress UITs: "The instruction to be mindful instead promotes an abandonment of mental control intentions ... This kind of therapy may have salutary effects because it replaces the use of a self-defeating mental control technique with a simple relaxation of the control motive" (p. 74). Consistent with this, Campbell-Sills, Barlow, Brown, and Hoffman (2006) found that in individuals with mood and anxiety disorders (including OCD), acceptance was associated with less distress than was expression suppression, that is, inhibition of the outward expression of emotion (Gross, 1998). Furthermore, researchers (Eifert \& Heffner, 2003; Levitt, Brown, Orsillo, \& Barlow, 2004) have found that acceptance fares better than suppression in reducing subjective distress in panic disorder patients and in individuals at risk for panic disorder (i.e., high in anxiety sensitivity). Thus, we would expect acceptance to lead to a reduction in the frequency of intrusive thoughts and distress associated with the thoughts. 
Relationship between Distress and Frequency of Intrusive thoughts

Distress and frequency of symptoms (including frequency of UITs) are found to be positively correlated in clinical samples of individuals with OCD (e.g., Foa, Kozak, Salkovskis, Coles, \& Amir, 1998) and in non-clinical samples (e.g., Salkovskis \& Harrison, 1984). In the non-clinical population, the frequency of symptoms is reported as being higher than the associated distress (Foa et al., 1998). Thus, consistent with cognitive-behavioral models of OCD, individuals without OCD tend to experience UITs but they are not as distressed by them because they do not appraise the UITs as negatively as do individuals with OCD (Salkovskis, 1996). Since they are less distressed by them, they tend to not engage in counterproductive attempts to get rid of them. For individuals with OCD, the counterproductive attempts to control UITs serve only to increase distress. Thus, they enter a relentless cycle of UITs, leading to increase in distress, which triggers counterproductive attempts to control the UITs, which in turn leads to an increase in distress and the frequency of UITs.

Taken together, we hypothesize that suppression will result in an increase in UIT frequency and distress once suppression attempts are relinquished. Moreover, we hypothesize that acceptance and focused-distraction will lead to a reduction in UIT frequency and distress. Given the exploratory nature of the creating-associates condition, we do not have a priori hypotheses regarding the effects of this condition.

Method

Overview and Design

Participants consisted of OCD patients and healthy controls as assessed by a clinical interview, the Structured Clinical Interview for DSM-IV (SCID, First, Spitzer, 
Gibbon, \& Williams, 1995). All participants completed a total of five sessions corresponding to a baseline assessment condition, a suppression condition and each of three alternative mental control conditions: focused-distraction, acceptance, and creatingassociates. The five sessions were separated by at least three days. The order of the suppression and alternative mental control conditions was randomized. This design enabled a within-subjects comparison of the three mental control conditions (suppression, focused-distraction, acceptance) and a between-subjects comparison of clinical and control groups. After the clinical interview, those participants who were eligible for the study were asked to identify confidentially, in writing, a personally relevant UIT during the first session. Each experimental session consisted of completing questionnaires, one thought monitoring task (TMT) in which participants were asked to follow the mental control instructions over two five-minute periods, followed by a TMT in which they were asked to think of anything they like. After each task, participants completed the same set of questionnaires. The total duration of the experiment for each participant was up to six hours: approximately two hours for the first session and under an hour for the remaining four sessions.

\section{Participants}

Twenty OCD patients (11 women, 9 men) and 20 healthy controls (13 women, 7 men) participated in the study. The mean age for OCD patients was 29 years $(S D=12)$ and for control participants was 30 years $(S D=9)$. Clinical participants were recruited at the OCD Center at Rogers Memorial Hospital in Oconomowoc, Wisconsin. Requirements for inclusion in the clinical group were a primary diagnosis of OCD, a Yale-Brown Obsessive-Compulsive Scale (Y-BOCS; Goodman, Price, Rasmussen, \& 
Mazure, 1989a, 1989b) total score greater than or equal to 16, and a Y-BOCS Obsessions score greater than or equal to 8. For this study, the mean Y-BOCS Obsessions score for the clinical group was $11.15(S D=3.13)$ and for the control group was $1.55(S D=2.04)$; the mean Y-BOCS Compulsions score for the clinical group was $10.75(S D=4.74)$ and for the control group was $1.05(S D=1.73)$. Of the clinical sample, nine $(45 \%)$ had a comorbid diagnosis of major depressive disorder, five $(25 \%)$ had a comorbid diagnosis of social anxiety disorder, three (15\%) had a comorbid eating disorder, and one $(5 \%)$ had comorbid specific phobia. Nineteen of the 20 OCD patients were on medication for the treatment of OCD. Participants in the clinical group had received cognitive-behavioral treatment prior to residential treatment for an average of 15.3 weeks $(S D=17.9)$. Participants were excluded if they had a history of psychotic disorders, bipolar disorder, or PTSD, or evidence of substance abuse within the past month. Furthermore, to limit potential overlap between the study's mental control tasks and aspects of CBT, we added to our exclusion criteria any prior exposure to the thought suppression demonstration, mindfulness/accpetance-based techniques, or attentional training therapy (which resulted in the exlusion of one potential participant who reported prior exposure to the thought suppression demonstration). Control participants recruited from the vicinity were either affiliates of Rogers Memorial Hospital or were individuals referred by affiliates. Control participants were screened for absence of psychological disorders. Participants received monetary inducement for participation (a total of $\$ 100$ for five sessions).

\section{Measures}

Structured Clinical Interview for DSM-IV (SCID; First, Spitzer, Gibbon, \& Williams, 1995). The SCID was used to assess the diagnostic status for all OCD patients 
and controls. It is a widely used instrument with acceptable psychometric properties (First et al., 1995). All interviews were administered by the first author, who had been trained in the administration of the SCID.

Yale-Brown Obsessive-Compulsive Scale (Y-BOCS; Goodman, Price, Rasmussen, \& Mazure, 1989a, 1989b). The Y-BOCS is a 10-item scale for rating obsessions and compulsions separately on five items (0-4) for a total score that varies from $0-40$. The Y-BOCS is a reliable and valid measure and is available in both clinician-rated and self-rated versions (Taylor, 1995). The self-report version was used in this study, and was administered in all five experimental sessions.

Thought Form. We developed a questionnaire for this study to assess (1) distress (“During this task, how distressed did you feel?"), (2) suppression effort ("During this task, how hard did you try to not think of your unwanted, intrusive, thought?’), and (3) compliance in following mental control instructions ("During this task, to what extent did you follow the instructions?") on a 1 (not at all) to 7 (very much) scale.

Measuring the frequency of UITs. Several studies of thought suppression have used participants' verbal reports of their stream of consciousness to measure the frequency of occurrence of UITs. It may be the case that for individuals with OCD, simple event marking is the most ecologically valid means of identifying the occurrence of UITs (Purdon \& Clark, 2000). As noted by Trinder and Salkovskis (1994) and Abramowitz et al. (2001), the monitoring activity necessary in event marking is analogous to OCD patients' hyper-vigilance for recurrences of their UITs. Thus, in the current research, the frequency of UITs was assessed using silent event marking: 
Participants were asked to follow instructions silently (without verbalizing their stream of consciousness) and to report occurrences of their UIT by pressing a clicker.

\section{Procedure}

During the first session, potential participants first completed the Y-BOCS. At this time eligible participants were asked questions about their psychiatric history and screened for current and past Axis I disorders using the SCID. Participants who did not fully meet eligibility criteria for the clinical or control groups were paid $\$ 25$ for their time and excluded from further participation.

Next, those participants who met all inclusion criteria were asked to identify their most unwanted intrusive thought. In order to ensure the identification of UITs and not worries or ruminations, the experimenter read the following detailed description of UITs to the participants (adapted from the Interpretation of Intrusions Inventory; OCCWG, 1997; 2001):

Now we would like you to focus on an unwanted thought. We are interested in your experience with unpleasant and unwanted thoughts or images or impulses that pop into your mind unexpectedly. Nearly everyone has such experiences, but people vary in how frequently these occur and how distressing they are. I'm going to read you some examples of the many possible negative intrusions that people have told us. Yours may be among these or may be different....[list of examples of UITs, Interpretation of Intrusions Inventory; OCCWG, 1997; 2001)]. Please note that we are not talking about daydreams or pleasant fantasies. Nor are we interested in general worries about health or finances or other family matters. Also, we are not talking about the sort of thoughts that accompany depression or 
low self-confidence. Rather, we are interested in thoughts, mental images or impulses that pop into your mind and that you experience as intrusive and inappropriate.

Once participants identified their UIT, they were asked to describe it in writing for two minutes. In order to ensure confidentiality, the experimenter left the room during this time, and informed the participant that the UIT description would be entered into the database by someone else, and that this database would not contain information linking the UIT description to the participant's name (instead, we would use a participant number).

Next, they performed a baseline thought monitoring task (TMT) for five minutes during which they were asked to think of anything they like. Participants performed this task alone in a featureless room while the experimenter was outside tracking the duration. During all TMTs for this study, participants were instructed to press a clicker (counter) every time they experienced an intrusion of their UIT:

The next task involves a thought monitoring task. So for the next five minutes, you can think of anything that comes to mind. During this time, your task is to record occurrences of your unwanted intrusive thought by pressing this clicker. Every time the thought occurs, record it by pressing this once. So, for the next five minutes, please record occurrences of your unwanted intrusive thought. It doesn't matter whether the thought occurs or not; just record the thought if it occurs. It is important that you continue this way for the full five minutes. At the end of the TMT, participants were asked to complete the questionnaires. 
For the next four sessions (each at least three days apart), participants were asked to follow the procedure mentioned below, the one difference being in the instruction they received prior to the TMTs. For each session, instructions for the TMT corresponded to one of the following conditions: Suppression of the UIT or one of three alternative mental control conditions (focused-distraction, acceptance, and creating-associates). Mental control task instructions were designed to ensure that the UIT was mentioned an equal number of times in each condition. The order of the mental control tasks was randomized for the participants. For sessions two through five, participants first read their own description of their UIT that they wrote in the first session. Next, they completed two five-minute periods of a TMT with one of suppression or the alternative mental control tasks. The experimenter repeated the instructions for the mental control tasks after the first five-minute period. For the suppression task, participants performed the five-minute TMTs while trying not to think of their UIT:

Suppression: During these five minutes, your task is to try not to think of your Unwanted Intrusive Thought. Try as hard as you can to not think of your Unwanted Intrusive Thought. Not thinking of your Unwanted Intrusive Thought is your primary task, but while you are performing this task, every time you notice that it pops to mind anyway, please press the clicker. It is important that you continue in the same way for the full five minutes.

For the alternative mental control task, participants performed the five-minute TMTs during which they were given one of the following corresponding instructions:

Focused Distraction: During these five minutes, your task is to not think of your Unwanted Intrusive Thought by focusing instead on the thought of a weekend 
with friends that you have either enjoyed in the past or hope to in the future. You should pick one specific weekend. Your task is to not think of your Unwanted Intrusive Thought by focusing on details of that weekend. Thinking of the weekend with friends is your primary task, but while you are performing this task, every time you notice that your Unwanted Intrusive Thought pops to mind, please press the clicker. It is important that you continue in the same way for the full five minutes.

Acceptance: During these five minutes, your task is to watch your Unwanted Intrusive Thought. Struggling with thoughts is like struggling with quicksand. Imagine that your Unwanted Intrusive Thought is coming out of your ears on little signs held by marching soldiers. I want you to allow the soldiers to march by in front of you, like a little parade. Do not argue with the signs, or avoid them, or make them go away. Just watch them march by. Visualizing your thoughts in this way is your primary task, but while you are performing this task, every time you notice that your Unwanted Intrusive Thought pops to mind, please press the clicker. It is important that you continue in the same way for the full five minutes. Creating-Associates: During these five minutes, your task is to create associations to your Unwanted Intrusive Thought. Associations to a thought are things related to that thought, e.g., an association to the thought of a beach may be the ocean, a family trip to the beach, or a beach ball. Your task is to create as many associations to your Unwanted Intrusive Thought as you can. The associations can be phrases or complete sentences but try to come up with as many different associations as you can. Coming up with associations is your primary task, but 
while you are performing this task, every time you notice that your Unwanted Intrusive Thought pops to mind, please press the clicker. It is important that you continue in the same way for the full five minutes.

After each of the two five-minute TMTs, participants completed the Thought Form. Next, participants completed one five-minute TMT in which they were asked to think of anything they like:

For the next five minutes, you can think of anything that comes to mind. There are no additional instructions. During this time, your task is to record occurrences of your unwanted intrusive thought by pressing this clicker. Every time the thought occurs, record it by pressing this once. So, for the next five minutes, please record occurrences of your unwanted intrusive thought. It doesn't matter whether the thought occurs or not; just record the thought if it occurs. It is important that you continue this way for the full five minutes.

The rationale for duplicating the mental control tasks (two five-minute segments) was to increase the strength of the mental control manipulation. Thus, each participant completed 10 minutes of the mental control tasks followed by one five-minute task with no additional mental control instructions. In all experimental sessions, after the noinstruction TMT, participants completed the questionnaires.

Results

\section{Unwanted Intrusive Thoughts}

UITs in the control group were classified into the following themes: five were themes of causing harm to self, nine of causing harm to others, and six of inappropriate sexual thoughts or images. For all participants in the clinical group, the UITs reflected 
their primary obsession target identified on the Y-BOCS Checklist. They were classified as follows: seven were themes of causing harm to self, nine of causing harm to others, two of inappropriate sexual thoughts or images, one of thoughts of order and symmetry, and one of thoughts of contamination. A non-significant chi-square test indicated that there was no difference between the clinical and control groups in UIT classifications, $\chi^{2}(4)=4.33, p>.36$.

\section{Baseline and Manipulation Checks}

Demographic and baseline differences in the clinical and control groups. The aim of the first group of analyses was to conduct manipulation checks and to examine baseline assumptions. First, analyses were conducted to confirm that symptom-related differences existed between the clinical and control groups at baseline, in the absence of demographic differences. A multivariate ANOVA was conducted to compare demographic and baseline differences between the OCD group and the healthy control group (Table 1). No between-group differences were found on the demographic measures. As expected, the OCD group scored significantly higher on all other baseline measures of interest.

Check for symptom severity change across sessions. Analyses were conducted to determine whether OCD symptom severity was stable across the mental control conditions. The purpose of this check was to rule out changes in symptom severity as a possible cause of changes in outcome measures of the study. To determine whether obsessive-compulsive symptoms were stable across the mental control conditions, a $4 \times 2$ mixed ANOVA was conducted with Y-BOCS scores as the dependent variable, mental control tasks (suppression, focused-distraction, acceptance, creating-associates) as the 
within-subjects variable, and clinical group (OCD, Control) as the between-subjects variable. Between-group differences were significant, $F(1,38)=88.57, \mathrm{p}<.001$. However, neither the mental control task $\times$ clinical group was significant, $F(3,114)=$ $.89, \mathrm{p}>.45$, nor was the main effect for mental control tasks, $F(3,114)=1.58, \mathrm{p}>.20$. These results suggest that any changes corresponding to the different mental control tasks were likely not due to a change in severity of obsessive-compulsive symptoms.

\section{Manipulation check of compliance to follow mental control instructions.}

Analyses were conducted to ensure comparable self-reported compliance to follow instructions across all mental control tasks. To compare self-reported compliance in the clinical and control groups, a $4 \times 2$ mixed ANOVA was conducted with mental control tasks (suppression, focused-distraction, acceptance, creating-associates) as the withinsubjects variable and clinical group ( $\mathrm{OCD}, \mathrm{Control})$ as the between-subjects variable. The mental control tasks $\times$ clinical group interaction was not significant, $F(1,38)=.19, p$ $>.66$, nor was the difference between mental control tasks, $F(1,38)=1.26, p>.27$, indicating that participants reported that they complied to a similar extent with all mental control instructions. However, for the creating-associates condition, 18 of the 20 individuals in the OCD group (and none in the non-anxious control group) reported being unable to generate a chain of associations away from the UIT and instead responded to the instructions by generating a circular chain of associations. For instance, in the control group, a typical example of a chain of association away from the UIT was (1) pushing someone in front of a train, (2) Amtrak, (3) trip to Chicago on Amtrak, (4) Chicago Bears; in the OCD group, a typical example of a chain of association was (1) stabbing someone with a knife, (2) I killed the person, (3) the knife I used to stab, (4) I killed the 
person with a knife. Thus, despite similar ratings of compliance across the OCD and control group, the fact that the OCD group was unable to generate a chain of associations away from the UIT renders it impossible to compare the differential effects of this technique in the OCD and control groups. Hence, the creating-associates condition was excluded from further analyses. ${ }^{1}$

Comparison of Effects of Suppression with Effects of Alternative Mental Control Tasks

The aim of the second group of analyses was to compare the experimental effects of the three mental control tasks. With these analyses we examined the primary hypotheses of the study, and tested the relative effects of suppression and the alternative mental control tasks for the following outcome measures: distress during task, distress post-task (and additional analyses for a direct comparison of distress during- versus posttask), UIT intrusions during task, UIT intrusions post-task (and additional analyses for a direct comparison of UIT intrusions during- versus post-task). The relative effects of the mental control tasks were examined using planned contrasts reflecting our expectation that suppression would yield worse outcomes (increase in distress and UIT frequency) than the two alternative mental control tasks. For all analyses, we included clinical group (OCD, control) as a between-subjects factor.

We first conducted all analyses with task order included as a factor. However, since task order did not appear in any significant effects (all $p \mathrm{~s}>.05$ ), the analyses reported below do not include task order as a factor. It is important to highlight that no significant order effects were found for distress during or post mental control task, thereby ruling out the possibility that participants were habituating to the UIT over multiple sessions. 
The two outcome measures - distress and UIT intrusion frequency-were measured during the baseline assessment, the mental control tasks (for two five-minute segments with mental control instructions), and after the mental control task (for one five-minute segment with no mental control instructions). There were no significant differences in the frequency and distress associated with UITs during the first and the second five-minute segments for any of the mental control tasks $(p s>.20)$. Hence, we computed mean values for distress and UIT intrusions during the first two five-minute segments in order to compare directly the during-task outcomes with the outcomes in the five-minute post-task segment.

Distress during task. To compare distress during the suppression condition with distress during the alternative mental control tasks, a $3 \times 2$ mixed ANOVA was conducted with mental control task (suppression, focused-distraction, acceptance) as the within-subjects variable, clinical group (OCD, Control) as the between-subjects variable, and baseline distress as a covariate. There was a significant difference between the OCD group and the control group, $F(1,37)=16.33, p<.001, \eta^{2}=.30$. However, the mental control tasks $\times$ clinical group interaction was not significant, $F(2,74)=.86, p>.42, \eta^{2}=$ .02. Thus, while the OCD group reported significantly greater distress during the mental control tasks than did the control group, this distress was similar across the mental control tasks for the OCD group, $F(2,36)=.14, p>.87, \eta^{2}=.01$, and for the control group, $F(2,36)=2.63, p>.12, \eta^{2}=.13$.

Distress post-task. To compare distress after the suppression condition with distress after the alternative mental control tasks, we conducted the same $3 \times 2$ mixed ANOVA as above. There was a significant difference between the OCD group and the 
control group, $F(1,37)=8.26, p<.01, \eta^{2}=.18$. The mental control tasks $\times$ clinical group interaction was significant, $F(2,74)=11.42, p<.001, \eta^{2}=.24$. A test of differences among mental control tasks was not significant for the control group, $F(2,36)$ $=1.64, p>.21, \eta^{2}=.08$, but was significant for the OCD group, $F(2,36)=6.54, p<.01$, $\eta^{2}=.28$. Planned pairwise comparisons for the OCD group yielded the following pattern that was consistent with hypothesis: Distress after suppression $(M=4.60)$ was greater than after focused-distraction $(M=2.30), t(19)=5.51, p<.001$, and after acceptance $(M$ $=1.85), t(19)=5.93, p<.001$. Thus, results for the OCD group revealed a very different picture for distress post-suppression compared to distress during suppression. Distress post-suppression was significantly higher than distress post-focused-distraction and acceptance.

Distress during versus post task. A $3 \times 2 \times 2$ mixed ANOVA was conducted with mental control task (suppression, focused-distraction, acceptance) and time (during, post) as within-subjects variables, clinical group (OCD, Control) as the between-subjects variable, and baseline distress as a covariate. The mental control task $\times$ time $\times$ clinical group interaction was significant, $F(2,74)=5.81, p<.01, \eta^{2}=.13$. For the control group, the mental control task $\times$ time interaction was not significant, $F(2,36)=.86, p>$ $.43, \eta^{2}=.05$, but for the OCD group it was significant, $F(2,36)=10.13, p<.004, \eta^{2}=$ .27. For the OCD group, we conducted a series of planned, paired, $t$-tests to evaluate the relative effects of the mental control tasks on distress during the task, as compared to post-task. In the OCD group (Figure 1) distress post-suppression $(M=4.60)$ was significantly greater than distress during suppression $(M=3.38), t(19)=2.66, \mathrm{p}<.02$. Distress during focused-distraction $(M=2.83)$ was not significantly different from 
distress post-focused-distraction $(M=2.30), t(19)=1.21, \mathrm{p}>.24$. Finally, distress postacceptance $(M=1.85)$ was significantly less than distress during acceptance $(M=3.38)$, $t(19)=2.97, \mathrm{p}<.01$. Results for the OCD group are consistent with the idea of a "rebound" of distress once suppression was abandoned. The opposite pattern was observed for distress in the acceptance task for which distress was significantly lower after the task than during it. There was no difference in distress during versus postfocused-distraction, and both values were low.

UIT intrusions during task. To compare UIT intrusions during the suppression condition with intrusions during the alternative mental control tasks, we conducted a $3 \times$ 2 mixed ANOVA. There was a significant difference between the OCD group and the control group, $F(1,37)=5.74, p<.02, \eta^{2}=.13$. However, the mental control tasks $\times$ clinical group interaction was not significant, $F(2,74)=1.66, p>.20$. The frequency of UITs was similar across mental control tasks for the control group, $F(2,36)=2.17, p>$ $.12, \eta^{2}=.11$, and for the OCD group, $F(2,36)=1.126, p>.29, \eta^{2}=.07$

UIT intrusions post-task. To compare the frequency of UIT intrusions after the suppression condition with intrusions after the alternative mental control tasks, we conducted the same $3 \times 2$ mixed ANOVA as above. There was a significant difference between the OCD group and the control group, $F(1,37)=6.47, p<.02, \eta^{2}=.15$. The mental control tasks $\times$ clinical group interaction was significant, $F(2,74)=4.28, p<.05$, $\eta^{2}=.11$. A test of differences among mental control tasks was not significant for the control group, $F(2,36)=.22, p>.70, \eta^{2}=.01$, but was significant for the OCD group, $F(2,36)=3.93, p=.05, \eta^{2}=.20$. In the OCD group, planned pairwise comparisons yielded the following pattern: The frequency of intrusions after the suppression $(M=$ 
7.85) was greater than after acceptance $(M=4.70), t(19)=2.34, p<.03$, but no different from the frequency of intrusions post-focused-distraction $(M=5.50), t(19)=1.38, p>$ .18. Thus, an analysis of UIT intrusions after the mental control tasks reveals worse outcomes for suppression as compared to acceptance, but not as compared to focuseddistraction.

UIT intrusions during versus post task. A $3 \times 2 \times 2$ mixed ANOVA was conducted with mental control task (suppression, focused-distraction, acceptance) and time (during, post) as within-subjects variables, clinical group (OCD, Control) as the between-subjects variable, and baseline intrusions as the covariate. The mental control task $\times$ time $\times$ clinical group interaction was not significant, $F(2,74)=2.56, p>.11, \eta^{2}=$ .06 . The mental control task $\times$ time interaction was not significant for the control group, $F(2,36)=1.29, p>.31, \eta^{2}=.06$, or for the OCD group, $F(2,36)=2.18, p>.10, \eta^{2}=.11$ (Figure 2).

Suppression effort. In order to rule out the possibility that individuals with OCD were suppressing their UIT while instructed to engage in the alternative mental control tasks, we compared self-reported effort exerted to suppress the UIT during suppression and the alternative mental control tasks. There was a significant difference between the OCD group and the control group, $F(1,37)=4.85, p<.04, \eta^{2}=.12$. As expected, the overall mental control tasks $\times$ clinical group interaction was not significant, $F(2,74)=$ $.04, p>.96, \eta^{2}=.001$. A similar pattern of effort exerted to suppress across the mental control tasks was found in the control group, $F(2,36)=4.99, p<.01, \eta^{2}=.34$, and the OCD group, $F(2,36)=7.79, p<.001, \eta^{2}=.32$. In the control group, effort towards suppression was greater in the suppression condition $(M=4.90)$ than in focused- 
distraction $(M=2.65), t(19)=3.28, p<.004$, and acceptance $(M=2.43), t(19)=3.60, p$ $<.002$. Similarly, in the OCD group: effort towards suppression was greater in the suppression condition $(M=6.10)$ than in focused-distraction $(M=4.00), t(19)=5.74, p<$ .001 , and acceptance $(M=3.98), t(19)=4.06, p<.001$.

In order to rule out the possibility that individuals with OCD spontaneously begin suppressing once they complete the mental control tasks, we compared self-reported effort exerted to suppress the UIT after suppression and the alternative mental control tasks. There was a significant difference between the OCD group and the control group, $F(1,37)=4.79, p<.04, \eta^{2}=.10$. However, the mental control tasks $\times$ clinical group interaction was not significant, and nor was the difference between mental control tasks for the OCD group or the control group (all $p \mathrm{~s}>.07$ ).

Taken together, the pattern for suppression effort during- and post-mental control tasks appears to be similar across the OCD and the control group: as expected, suppression effort during the suppression condition is greater than during the other conditions, but once mental control is relinquished, there is no difference in effort exerted toward suppression in the different tasks. Thus, there were no significant lingering effects of the suppression task on continued effort to suppress.

\section{Discussion}

Results of the study confirm the negative effects of suppression in OCD. For the OCD group, although suppression of intrusive thoughts did not lead to their rebound, it did indeed lead to an exacerbation in distress; the effort expended towards suppression failed to alleviate anxiety, which is the putative reason why individuals with OCD engage in suppression. These results suggest the idea of a "rebound" of distress for the OCD 
group once suppression is abandoned. This is consistent with Wegner and Gold's (1995) finding of an "emotional rebound" (measured by skin conductance) in the absence of a "cognitive rebound" (measured by self-reported intrusion frequency) for emotionally relevant thoughts. It is also consistent with Roemer and Borkovec's (1994) study, which showed that suppression of worry-related and depressive thoughts is associated with greater anxiety but not greater thought frequency. An important point to note is that the OCD group had significantly more frequent UIT intrusions both during- and postsuppression than did the control group. This is consistent with findings from Janeck and Calamari's (1999) study in which OCD patients reported more intrusions than did controls regardless of whether they attempted to suppress their UIT. One possibility is that OCD patients continue to suppress even when instructed to stop suppressing (e.g., Purdon et al., 2005). However, in view of the fact that in the present study, the OCD group reported exerting less effort toward suppression in the post-suppression period than during suppression, a more fitting interpretation is that OCD patients are ineffective in suppressing their UITs whether or not they are actively attempting to suppress.

For the most part, results of this study reveal that the different mental control tasks did not affect the outcome measures differentially in the healthy, control group. One possibility is that the study was insufficiently powered to detect significant differences in the effects of the mental control tasks in the control group. However, for the OCD group, the sample size was sufficient to detect within-group differences. On the whole, it appears that suppression fared poorly, whereas focused-distraction and acceptance fared well in the management of intrusive thoughts. This was reflected clearly in the pattern of distress once mental control was relinquished: the suppression 
task led to a rebound of distress, whereas the acceptance task led to a reduction in distress; in the focused-distraction task, participants experienced low distress both during and after the task.

Results from the acceptance task are consistent with findings from the nonclinical study by Marcks and Woods (2005) in which suppression resulted in a post-task increase in distress and acceptance resulted in a post-task decrease in distress (but not intrusions). The current study confirms these findings in a clinical sample of OCD patients: While suppression did not fare particularly worse than acceptance during the task, once mental control was relinquished, distress after suppression increased significantly whereas distress after acceptance decreased significantly. These effects were specific for distress and were not found for frequency of intrusions.

The effectiveness of focused distraction mirrors the results from the second experiment in the original "white bear" study (Wegner et al., 1987): Suppression is counterproductive except if attempted by means of focusing on one chosen source of distraction. These results are also consistent with a study conducted with OCD patients in which focused distraction was shown to be more effective in alleviating distress than was neutralization (Salkovskis et al., 2003).

A few theoretical issues are raised by this evidence for the effectiveness of focused distraction to manage UITs. Whereas the effectiveness of the acceptance technique can be understood in terms of exposure to the UIT, a technique that we know is effective for dealing with UITs, focused distraction away from UITs appears to be in direct contradiction to the concept of exposure. One possibility is that focused distraction works well in the short term but loses potency as the object of focus loses its salience. 
This hypothesis can be tested empirically in future research using a long-term follow-up design in which participants are asked to maintain a diary of intrusions of the UIT over a longer period following the experimental manipulation; for instance, Gerearts and colleagues (2006) showed that a group identified as repressive copers were successfully able to suppress negative thoughts temporarily in the lab but experienced a rebound over a seven day follow-up. Another possibility is that the mechanism underlying both the focused-distraction and the acceptance techniques used in this study is an increase in attentional control. Eysenck and colleagues (2007) have discussed the ways in which anxiety adversely affects attentional control, including the monitoring of working memory. At a basic level, both the focused-distraction and acceptance tasks in this study are similar in that they require the maintenance of a thought or image in working memory over a sustained period.

Our study shows that distraction provides temporary relief from distress and intrusions, but a question that remains unanswered is whether or not all forms of distraction serve to undermine exposure and hence maintain anxiety in the long run. Penfold and Page (1999) examined the effects of distraction during in vivo exposure with phobic participants and found that exposure with distraction resulted in the greatest decrease in within-session anxiety. Johnstone and Page (2004) showed the same results within and between sessions and explained this seemingly contradictory effect of distraction on exposure as a function of increased self-efficacy. On the other hand, two studies using OCD participants found that within-session reductions in anxiety failed to generalize to between-session reductions in those who engaged in distraction (Grayson, Foa, \& Steketee, 1982; 1986). Worse longer-term outcomes for distraction during 
exposure has also been found in other anxiety disorders (e.g., Craske, Street, \& Barlow, 1989: Kamphuis \& Telch, 2000). Thus, we have consistent evidence for the effectiveness of distraction in the short term and inconsistent findings regarding longer-term outcomes. Further research is needed to determine whether or not focused distraction may be used effectively in treatment.

One limitation of our study is that we were unsuccessful in implementing our exploratory condition, the creating-associates technique. In general, individuals in the OCD group were unable to generate a chain of associations away from their intrusive thoughts. One possibility for future research is to include, prior to evaluating the effects of the technique, a training phase in which individuals are trained to generate chains of associations away from a thought. This was not possible in the current study, which was intended to examine mental control techniques that can be used with minimal instruction.

Our study design is consistent with recent trends in the development of cognitive interventions in the treatment of OCD. The behavioral treatment of exposure with response prevention is considered the psychological treatment of choice for OCD, but 20$30 \%$ of patients are either resistant to this form of treatment or refuse it (Foa, Franklin, \& Kozak, 1998). Foa and Wilson (2001) suggest that exposure exercises may be supplemented by cognitive techniques, such as acceptance exercises, for a more comprehensive, and potentially more palatable, treatment approach. Results of the current research are consistent with this suggestion.

Further research is needed to identify specific treatment strategies for particular subtypes of OCD. For instance, Lee and Kwon (2003) have proposed two types of obsessions - autogenous and reactive obsessions - which they suggest are associated with 
two distinct subtypes of OCD. Autogenous obsessions are perceived as ego-dystonic and irrational (e.g., sexual obsessions), and compulsions are aimed at controlling the obsession or suppressing it from consciousness (e.g., covert rituals). Reactive obsessions are perceived as more realistic (e.g., contamination), and compulsions are aimed at preventing the anticipated negative consequences of the obsession (e.g., washing) rather than getting rid of the obsession itself. Lee and Kwon propose that the etiology of autogenous obsessions is associated with appraisals about the importance of thoughts and the need to control thoughts whereas the etiology of reactive obsessions is associated with appraisals about personal responsibility. One possibility is that these two subtypes may be used as the basis for specifically tailored interventions to improve treatment: For instance, Lee and Kwon suggest that patients with autogenous obsessions may be better treated with more cognitive approaches (e.g., acceptance and focused distraction) whereas those with reactive obsessions may be better suited for the more traditional exposure and response prevention.

Important to note is that in the current study, the clinical sample included a higher than expected proportion of obsessions of harm to self and others (autogenous obsessions), as compared to other obsessional themes, such as contamination, or symmetry. To the extent that this may reflect a non-representative sample of OCD patients, these results may be less generalizable to OCD patients whose primary obsessions are reactive. Further research, with a larger sample, including representative proportions of the major OCD subtypes, is needed to address the question of specificity of these results for particular subtypes. 
Another limitation of our study that is related to generalizability of our findings is prior exposure to CBT. Participants in our clinical group had received, on average, 3-4 months of cognitive-behavioral treatment prior to entering residential treatment for OCD, and hence prior to beginning our study (we recruited participants upon entering the residential treatment program). Thus, by definition, our clinical group comprised individuals who were non-responsive to CBT. In order to limit potential overlap between our study tasks and CBT, we excluded participants with prior exposure to the mental control tasks used in the study. However, it remains to be seen whether results of our study are replicated in individuals with OCD who are not non-responders to CBT.

In a comprehensive review of cognitive vulnerability to emotional disorders, Mathews and MacLeod (2005) noted: "Rather than assume that all top-down control is ineffective, we suggest that some types of attempted cognitive control may be detrimental, whereas others are more likely to be beneficial. An important area for future research is to distinguish productive from counterproductive control strategies" (p. 178). The research presented here reflects this very undertaking. We conclude that the focus of future research should not so much be on whether or not suppression occurs; we know it occurs in normal experience and that OCD patients consistently report a higher propensity to suppress UITs. That suppression is counterproductive in OCD, or at the very least ineffective, also appears to be fairly incontrovertible, particularly with regard to the distress it causes and the mental effort it requires. In future research we need to better understand the contexts in which acceptance and focused distraction techniques can used as more favorable alternatives. 


\section{References}

Abramowitz, J.S., Tolin, D.F., \& Street, G.P. (2001). Paradoxical effects of thought suppression: A meta-analysis of controlled studies. Clinical Psychology Review, 21, 683-703.

Bach, P., \& Hayes, S. C. (2002). The use of acceptance and commitment therapy to prevent the rehospitalization of psychotic patients: A randomized controlled trial. Journal of Consulting and Clinical Psychology, 70, 1129-1139.

Bogels, S. M. (2006). Task concentration training versus applied relaxation, in combination with cognitive therapy, for social phobia patients with fear of blushing, trembling, and sweating. Behaviour Research and Therapy, 44, 11991210.

Bogels, S. M., Mulkens, S., \& De Jong, P. J. (1997). Task concentration training and fear of blushing. Clinical Psychology and Psychotherapy, 4, 251-258.

Campbell-Sills, L., Barlow, D. H., Brown, T. A., Hofmann, S. G. (2006). Effects of suppression and acceptance on emotional responses of individuals with anxiety and mood disorders. Behaviour Research and Therapy, 44, 1251-1263.

Clark, D. A. (2004). Cognitive-behavioral therapy for OCD. New York: Guilford Press.

Clark, D. A. (2005). Intrusive thoughts in clinical disorders: Theory, research, and treatment. New York: Guilford Press.

Craske, M. G., Street, L. L. \& Barlow, D. H. (1989). Instructions to focus upon or distract from internal cues during exposure treatment of agoraphobic avoidance. Behaviour Research and Therapy, 27, 663-672. 
Dalgleish, T., \& Yiend, J. (2006). The effects of suppressing a negative autobiographical memory on concurrent intrusions and subsequent autobiographical recall in dysphoria. Journal of Abnormal Psychology, 115(3), 467-473.

Eifert, G. H., \& Heffner, M. (2003). The effects of acceptance versus control contexts on avoidance of panic-related symptoms. Journal of Behavior Therapy and Experimental Psychiatry, 34, 293-312.

Eysenck, M. W., Derakshan, N., Santos, R., \& Calvo, M. G. (2007). Anxiety and cognitive performance: Attentional control theory. Emotion, 7, 336-53.

First, M. B., Spitzer, R. L., Gibbon, M., \& Williams, J. B. W. (1995). Structured Clinical Interview for DSM-IV Axis I Disorders.

Foa, E. B., Franklin, M. E., \& Kozak, M. J. (1998). Psychosocial treatments for obsessive-compulsive disorder. Literature review. In R. P. Swinson, M. M. Antony, S. Rachman, \& M. A. Richter (Eds.), Obsessive compulsive disorder: Theory, research and treatment (pp. 258-276). New York: Guilford Press.

Foa, E. B. \& Wilson, E. (2001). Stop Obsessing! How to overcome your obsessions and compulsions. New York: Bantam.

Freeston, M. H., \& Ladoucer, R. (1997). What do patients do with their obsessive thoughts? Behaviour Research and Therapy, 35, 335-348.

Geraerts, E., Merckelbach, H., Jelicic, M., \& Smeets, E. (2006). Long term consequences of suppression of intrusive thoughts and repressive coping. Behaviour Research and Therapy, 44, 1451-1460.

Goodman, W. K., Price, L. H., Rasmussen, S. A., Mazure, C., Fleischmann, R. L., Hill, C. L., Heninger, G. R., \& Charney, D. S. (1989a). The Yale-Brown Obsessive 
Compulsive Scale: II. Development, use, and reliability. Archives of General Psychiatry, 46, 1006-1011.

Goodman, W. K., Price, L. H., Rasmussen, S. A., Mazure, C., Delgado, P., Heninger, G. R., \& Charney, D. S. (1989b). The Yale-Brown Obsessive Compulsive Scale: II. Validity. Archives of General Psychiatry, 46, 1012-1016.

Grayson, J. B., Foa, E. B. \& Steketee, G. S. (1982). Habituation during exposure treatment: Distraction vs attention-focusing. Behaviour Research and Therapy, $20,323-328$.

Grayson, J. B., Foa, E. B. \& Steketee, G. S. (1986). Exposure in vivo of obsessivecompulsives under distracting and attention-focusing conditions: Replication and extension. Behaviour Research and Therapy, 24, 475-479.

Gross, J. J. (1998). Antecedent- and response-focused emotion regulation: Divergent consequences for experience, expression, and physiology. Journal of Personality and Social Psychology, 74, 224-237.

Guthrie, R., \& Bryant, R. A. (2000). Attempting suppression of traumatic memories over extended periods in acute stress disorder. Behaviour Research and Therapy, 38(9), 899-907.

Harvey, A. G., \& Bryant, R. A. (1998). The effect of attempted thought suppression in acute stress disorder. Behavior Research and Therapy, 36, 583-590.

Hayes, S. C., Strosahl, K. D., \& Wilson, K. G. (1999). Acceptance and commitment therapy: An experiential approach to behavior change. New York: Guilford Press. 
Janeck, A. S., \& Calamari, J. E. (1999). Thought suppression in obsessive-compulsive disorder. Cognitive Therapy and Research, 23, 497-509.

Johnstone, K. A., \& Page, A. C. (2004). Attention to phobic stimuli during exposure: The effect of distraction on anxiety reduction, self-efficacy and perceived control. Behaviour Research and Therapy, 42, 249-275.

Kabat-Zinn, J., Massion, A. O., Kristeller, J., Peterson, L. G., Fletcher, K. E., Pbert, L., et al. (1992). Effectiveness of a meditation-based stress reduction program in the treatment of anxiety disorders. American Journal of Psychiatry, 149, 936-944.

Kamphuis, J. H. \& Telch, M. J. (2000). Effects of distraction and guided threat reappraisal on fear reduction during exposure-based treatments for specific fears. Behaviour Research and Therapy, 38, 1163-1181.

Levitt, J. T., Brown, T. A., Orsillo, S. M., \& Barlow, D. H. (2004). The effects of acceptance versus suppression of emotion on subjective and psychophysiological response to carbon dioxide challenge in patients with panic disorder. Behavior Therapy, 35, 747-766.

Ma, S. H., \& Teasdale, J. D. (2004). Mindfulness-based cognitive therapy for depression: Replication and exploration of differential relapse prevention effects. Journal of Consulting and Clinical Psychology, 72, 31-40.

Marcks, B. A. \& Woods, D. W. (2005). A comparison of thought suppression to an acceptance-based technique in the management of personal intrusive thoughts: a controlled evaluation. Behaviour Research and Therapy, 43, 433-445.

Mathews, A., \& MacLeod, C. (2005). Cognitive vulnerability to emotional disorders. Annual Review of Clinical Psychology, 1, 167-195. 
Mulkens, S., Bogels, S. M., de Jong, P. J., \& Louwers, J. (2001). Fear of blushing : Effects of task concentration training versus exposure in vivo on fear and psychology. Journal of Anxiety Disorders, 15, 413-432.

Najmi, S., \& Wegner, D. M. (2008). The gravity of unwanted thoughts: Asymmetric priming effects in thought suppression. Consciousness \& Cognition: An International Journal, 17, 114-124.

Obsessive Compulsive Cognitions Working Group. (1997). Cognitive assessment of obsessive-compulsive disorder. Behaviour Research and Therapy, 35, 667-681.

Obsessive Compulsive Cognitions Working Group. (2001). Development and initial validation of the obsessive beliefs questionnaire and the interpretation of intrusions inventory. Behaviour Research and Therapy, 39, 987-1006.

Papageorgiou, C., \& Wells, A. (1998). Effects of attention training on hypochondriasis: a brief case series. Psychological Medicine, 28, 193-200.

Papageorgiou, C., \& Wells, A. (2000). Treatment of recurrent major depression with attention training. Cognitive and Behavioral Practice, 7, 407-413.

Penfold, K., \& Page, A. C. (1999). The effect of distraction on within-session anxiety reduction during brief in vivo exposure for mild blood-injection fears. Behavior Therapy, 30, 607-621.

Purdon, C. L. (2001). Appraisal of obsessional thought recurrences: Impact on anxiety and mood state. Behavior Therapy, 32, 47-64.

Purdon, C. L., \& Clarke, D. A. (2000). White bears and other elusive intrusions: Assessing the relevance of thought suppression for obsessional phenomena. Behavior Modification, 24, 425-453. 
Purdon, C. L., Rowa, K., \& Antony, M. M. (2005). Thought suppression and its effects on thought frequency, appraisal and mood state in individuals with obsessivecompulsive disorder. Behaviour Research and Therapy, 43, 93-108.

Rassin, E. (2005). Thought suppression. New York: Elsevier.

Roemer, L., \& Borkovec, T. D. (1994). Effects of suppressing thoughts about emotional material. Journal of Abnormal Psychology, 103, 467-474.

Roemer, L., \& Orsillo, S. M. (2002). Expanding our conceptualization of and treatment for generalized anxiety disorder: Integrating mindfulness/acceptance-based approaches with existing cognitive-behavioral models. Clinical Psychology: Science and Practice, 9, 54-68.

Salkovskis, P. M. (1996). Cognitive-behavioural approaches to the understanding of obsessive-compulsive problems. In R. M. Rapee (Ed.), Current controversies in the anxiety disorders (pp. 103-133). New York: Guilford Press.

Salkovskis, P. M. \& Campbell, P. (1994). Thought suppression induces intrusion in naturally occurring negative intrusive thoughts. Behaviour Research and Therapy, 32, 1-8.

Salvokskis, P. M., \& Harrison, J. (1984). Abnormal and normal obsessions - A replication. Research and Therapy, 23, 571-584.

Salkovskis, P. M., Thorpe, S. J. Wahle, K., Wroe, A. L., \& Forrester, E. (2003). Neutralizing increases discomfort associated with obsessional thoughts: An experimental study with obsessional patients. Journal of Abnormal Psychology, 112, 709-715. 
Segal, Z. V., Williams, J. M. G., \& Teasdale, J. D. (2002). Mindfulness and the prevention of depression: A guide to the theory and practice of mindfulnbessbased cognitive therapy. New York: Guilford Press.

Siegle, G. J., Ghinassi, F., \& Thase, M. E. (2007). Neurobehavioral therapies in the 21st century: Summary of an emerging field and an extended example of cognitive control training for depression. Cognitive Therapy and Research, 31, 235-262.

Shipherd, J. C., \& Beck, J. G. (1999). The effects of suppressing trauma-related thoughts on women with rape-related posttraumatic stress disorder. Behaviour Research and Therapy, 37, 99-112.

Teasdale, J. D., Segal, Z. V., Williams, J. M. G., Ridgeway, V. A., Soulsby, J. M., \& Lau, M. A. (2000). Prevention of relapse/recurrence in major depression by mindfulness-based cognitive therapy. Journal of Consulting and Clinical Psychology, 68, 615-623.

Tolin, D. F., Abramowitz, J. S., Przeworski, A., \& Foa, E. B. (2002). Thought suppression in obsessive-compulsive disorder. Behaviour Research and Therapy, 40, 1255-1274.

Trinder, H., \& Salkovskis, P. M. (1994). Personally relevant intrusions outside the laboratory: long-term suppression increases intrusion. Behaviour Research and Therapy, 32, 833-842.

Twohig, M. P. (2008). A randomized clinical trial of acceptance and commitment therapy versus progressive relaxation training in the treatment of obsessive compulsive disorder. Dissertation Abstract International: Section B: The Sciences and Engineering, 68, 4850. 
Twohig, M. P., Hayes, S. C., \& Masuda, A. (2006). Increasing Willingness to Experience Obsessions: Acceptance and Commitment Therapy as a Treatment for ObsessiveCompulsive Disorder. Behavior Therapy, 37, 3-13.

Watson, C., \& Purdon, C. (2008). Attention Training in the reduction and reappraisal of intrusive thoughts. Behavioural and Cognitive Psychotherapy, 36, 61-70.

Wegner, D. M. (1989). White bears and other unwanted thoughts: Suppression, obsession, and the psychology of mental control. New York: Viking/Penguin.

Wegner, D. M. (1994). Ironic processes of mental control. Psychological Review, 101, 34-52.

Wegner, D. M., \& Gold, D. B. (1995). Fanning old flames: Emotional and cognitive effects of suppressing thoughts of a past relationship. Journal of Personality and Social Psychology, 68, 782-792.

Wegner, D. M., Schneider, D. J., Carter, S., III, \& White, L. (1987). Paradoxical effects of thought suppression. Journal of Personality and Social Psychology, 53, 5-13.

Wegner, D. M., Schneider, D. J., Knutson, B., \& McMahon, S. R. (1991). Polluting the stream of consciousness: The effect of thought suppression on the mind's environment. Cognitive Therapy and Research, 15, 141-152.

Wegner, D. M., \& Zanakos, S. (1994). Chronic thought suppression. Journal of Personality, 62, 615-640.

Wells, A. (2000). Emotional disorders and metacognition: Innovative cognitive therapy. Chichester, UK: Wiley. 
Wells, A., \& Davies, M. I. (1994). The thought control questionnaire: A measure of individual differences in the control of unwanted thoughts. Behaviour Research and Therapy, 32, 871-878.

Wells, A., White, J., \& Carter, K. (1997). Attention training: effects on anxiety and belief in panic and social phobia. Clinical Psychology and Psychotherapy, 4, 226-232.

Wenzlaff, R. M. (2005). Seeking solace but finding despair: The persistence of intrusive thoughts in depression. In Clark, D. A. (Ed.), Intrusive thoughts in clinical disorders: Theory, research, and treatment, (pp. 54-85). New York: Guilford Press.

Wenzlaff, R. M., \& Bates, D. E. (1998). Unmasking a cognitive vulnerability to depression: how lapses in mental control reveal depressive thinking. Journal of Personality and Social Psychology, 75, 1559-1571.

Wenzlaff, R. M., \& Eisenberg, A. R. (2001). Mental control after dysphoria: evidence of a suppressed, depressive bias. Behavior Therapy, 32, 27-45.

Wenzlaff, R. M., Meir, J., \& Salas, D. M. (2002). Thought suppression and memory biases during and after depressive moods. Cognition and Emotion, 16, 403-422.

Wenzlaff, R. M., Wegner, D. M., \& Roper, D. W. (1988). Depression and mental control: The resurgence of unwanted negative thoughts. Journal of Personality and Social Psychology, 55, 882-892.

Wenzlaff, R. M., \& Wegner, D. M. (2000). Thought suppression. In S. T. Fiske (Ed.), Annual review of psychology: Vol. 51, (pp. 59-91). Palo Alto, CA: Annual Reviews. 


\section{Notes}

1. We conducted exploratory analyses to examine the effects of the creating-associates condition in the non-clinical group. This information is available upon request to the first author. 
Table 1

Demographic and baseline differences between OCD and control groups

\begin{tabular}{|c|c|c|c|c|c|}
\hline & \multicolumn{2}{|c|}{$\begin{array}{c}\text { OCD } \\
(n=20)\end{array}$} & \multicolumn{2}{|c|}{$\begin{array}{l}\text { Control } \\
(n=20)\end{array}$} & \\
\hline & $M$ & $S D$ & $M$ & $S D$ & \\
\hline Age & 28.65 & 11.95 & 29.90 & 8.58 & $p>.71$ \\
\hline Sex & $9 \mathrm{M}, 11 \mathrm{~F}$ & & $6 \mathrm{M}, 14 \mathrm{~F}$ & & $\chi^{2}(1)=.96, p>.33$ \\
\hline Y-BOCS Obsessions & 11.15 & 3.13 & 1.55 & 2.04 & $p<.001$ \\
\hline Y-BOCS Compulsions & 10.75 & 4.74 & 1.05 & 1.73 & $p<.001$ \\
\hline Y-BOCS Total & 21.90 & 7.49 & 2.60 & 3.45 & $p<.001$ \\
\hline UIT Intrusions & 8.55 & 9.64 & 1.90 & 2.47 & $p<.01$ \\
\hline Distress & 4.35 & 2.25 & 1.85 & 1.31 & $p<.001$ \\
\hline
\end{tabular}




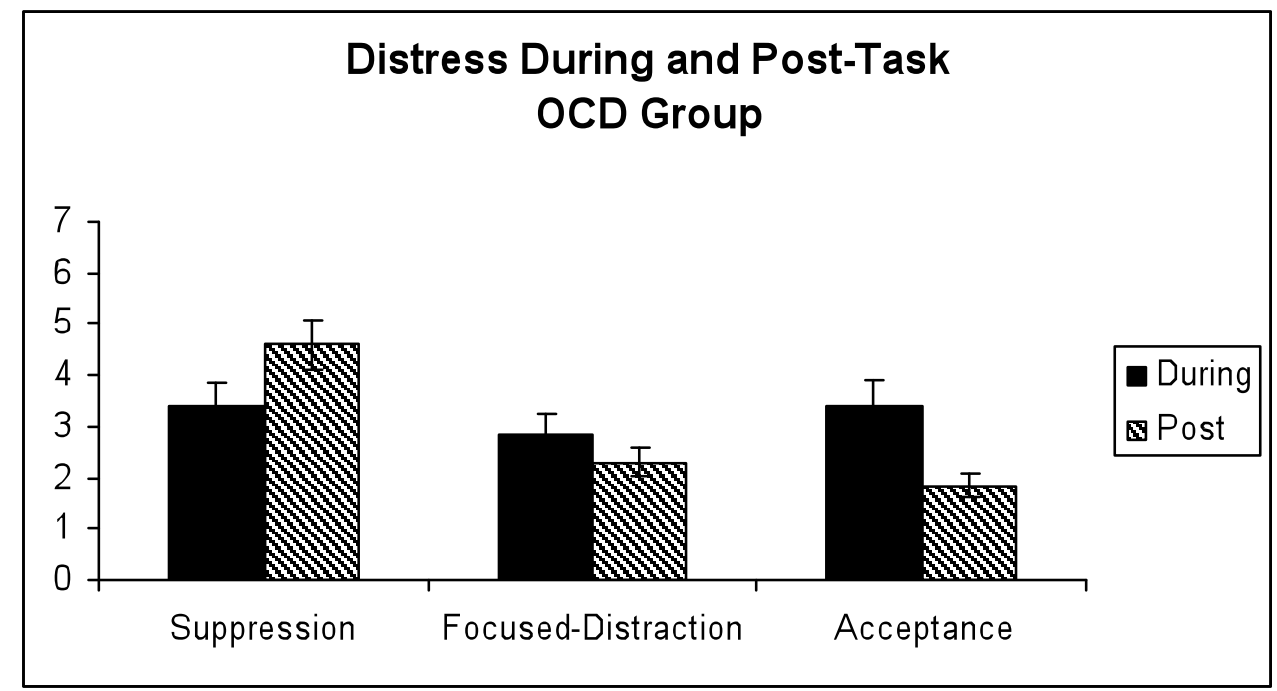

Figure 1. Distress during- and post-mental control tasks in the OCD group.

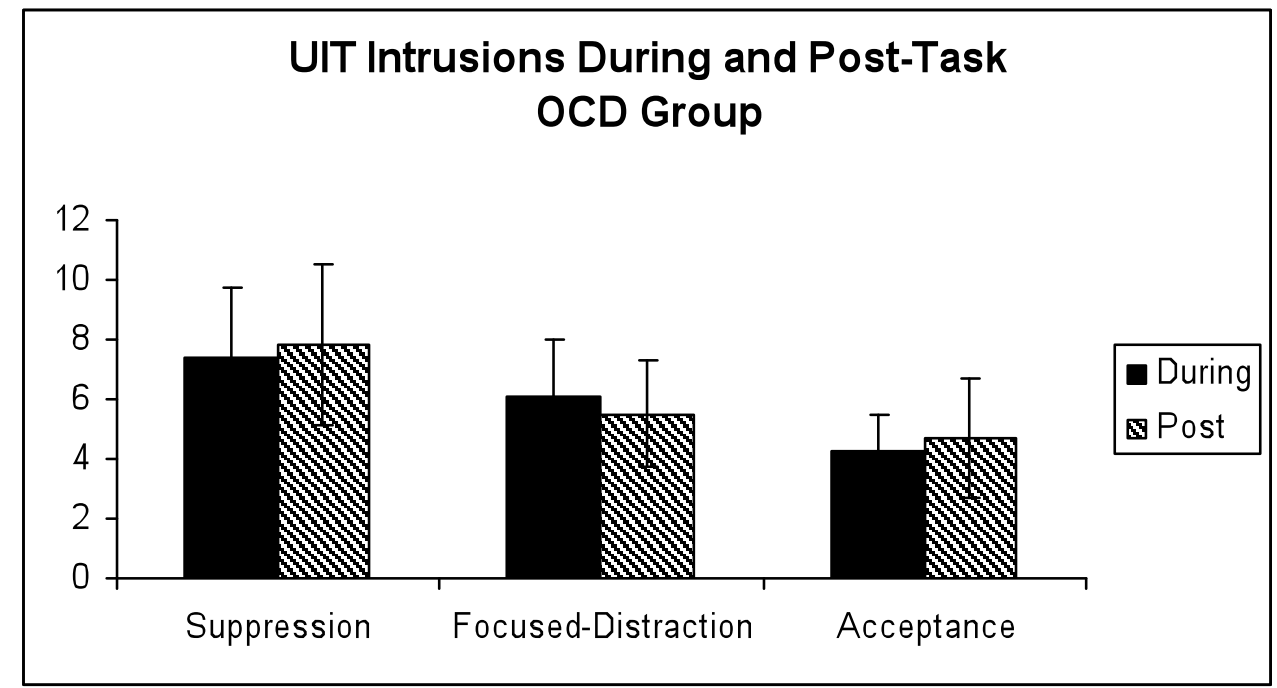

Figure 2. UIT intrusions during- and post-mental control tasks in the OCD group. 